[nt. J. Agril. Res. Innov. Tech. 10(2): 38-46, December 2020 Available online at https://ijarit.webs.com DOI: https://doi.org/10.3329/ijarit.v10i2.51575 https://www.banglajol.info/index.php/IJARIT

\title{
First report on black spot disease of Phyllanthus emblica L. fruits caused by Thielaviopsis paradoxa in Bangladesh
}

\author{
M.M. Sikder, M.S. Ahmmed, A. Sultana and N. Alam* \\ Received 30 May 2020, Revised 31 August 2020, Accepted 24 December 2020, Published online 31 December 2020
}

\begin{abstract}
A B S T R A C T
Fruit spot disease of Phyllanthus emblica L. is one of theproblems, which reduce the quality of the fruits at pre-harvest period. Fungal pathogen was isolated using tissue planting methods during November 2016 to December 2017. The fungus, Thielaviopsis paradoxa was identified using both morphological and molecular characterization based on internal transcribe spacer (ITS) region of ribosomal DNA (rDNA). Mycelial growth of the isolated fungus was evaluated on six different fungal culture media viz, potato sucrose agar (PSA), Richard agar (RA), carrot agar (CA), potato dextrose agar (PDA), honey peptone agar (HPA) and Hansen's agar (HA) in which RA and HPA media provided the utmost growth. The optimum temperature of the fungus was recorded at 25 to $35^{\circ} \mathrm{C}$. Alternate cycle of $12 \mathrm{~h} / 12 \mathrm{~h}$ light dark and neutral to basic $\mathrm{pH}$ was preferred by the studied fungus. Aqueous crude extracts of three plants (garlic, black cumin, and turmeric) were evaluated against the isolated fungus in which the highest inhibition was recorded due to garlic extract. Two food preservatives (sodium benzoate and vinegar) were also tested in which sodium benzoate (100 mM) was most efficient for the inhibition of T. paradoxa. Therefore, garlic and food preservative-sodium benzoate could be used to control this fungal growth associated with amla fruits. To the best of our knowledge, occurrence of $T$. paradoxa on amla fruits is a new record in Bangladesh.
\end{abstract}

Keywords: Amla, Fruit spot disease, Fungal biology, Thielaviopsis paradoxa, Molecular characterization.

Department of Botany, Faculty of Biological Sciences, Jahangirnagar University, Savar, Dhaka-1342, Bangladesh.

*Corresponding author's email: mnabotju@yahoo.com (N. Alam)

Cite this article as: Sikder, M.M., Ahmmed, M.S., Sultana, A. and Alam, N. 2020. First report on black spot disease of Phyllanthus emblica L. fruits caused by Thielaviopsis paradoxa in Bangladesh. Int. J. Agril. Res. Innov. Tech. 10(2): 38-46. https://doi.org/10.3329/ijarit.v10i2.51575

\section{Introduction}

Amla known as Phyllanthus emblica L. belongs to the family Euphorbiaceae. This plant is originally native to India but also found in Pakistan, Uzbekistan, Sri Lanka, Southeast Asia China, West India, Japan, Madagascar and Malaysia (Krishnaveni and Mirunalini, 2012). In Bangladesh, it is cultivated in dry forests of Chattogram, Chattogram Hill Tracts, Cox's Bazar, Sylhet, Dhaka-Tangail Sal forest, Dinajpur and homestead forest. It has an important position in Ayurveda- an Indian indigenous system of medicine, which prevents innumerable health disorders and used as a possible food additive or in nutraceuticals and biopharmaceutical industries (Dasaroju and Gottumukkala, 2014). Fruits contain high levels of sugars and nutrient elements and their low $\mathrm{pH}$ value make them susceptible for fungal attack and are being rotted (Singh and Sharma, 2007). Fungi not only blemish or cause rot to a number of fruits but also reduce their market value. Fungi also produce several toxins that may concern to human health. Pre-harvest fruit diseases generally occur in colder month January. Fungal diseases of amla fruit causes rot, blue mould, green mould diseases. These rot diseases occurred due to attacked of some pre-harvest and post-harvest pathogens, such as- Pestalotiopsis sp., Aspergillus sp., Penicillium sp., Cladosporium sp., Acremonium sp., Fusarium sp., Rhizopus sp., Mucor sp., Curvularia sp., Paecilomyces sp., etc. Among these, Pestalotiopsis sp. was discovered as pre-harvest pathogen, which creates rot disease of amla fruit (Verma and Verma, 2015).

In Bangladesh, there was no record on association of genus- Thielaviopsis (family Ceratocystidaceae) on amla fruits. However, this notorious fungus has been known to having wide host ranges and causes disease on different plants such as pineapple black root, cacao wilt, kiwifruit plant wilt and responsible for economic losses 
(Engelbrecht et al., 2007; Piveta et al., 2016; Oliveira et al., 2018). Paulin-Mahady et al. (2002) reported Certocystis adiposa in Prunus; C. albofundus in Acacia; C. coerulescens and $C$. pinicola in Pinus; $C$. eucalypti in Eucalyptus; $C$. paradoxa in Ananas; and $C$. radicicola in Phoenix. Ceratocystis manginecans was found as responsible for destructive monga wilt disease in Oman and Pakistan (Wyk et al., 2007).

Plants extracts and essential oils perform antifungal activity against an extensive number of fungal diseases (Javaid and Iqbal, 2014; Javaid and Rauf, 2015). The antifungal activity of garlic extracts applied directly and through volatile release was tested against the growth of postharvest pathogens (Daniel et al., 2015). Turmeric used against fungal activity helps to control fungal spoilage and fungal growth. Extract of turmeric reduce fungal activity and most effective against Fusarium sp. (Moghadamtousi et al., 2014). Moreover, several preservatives are known to use to reduce the fungal activity. Many preservatives such as sodium benzoate, sodium bi-carbonate, sodium chloride, sodium nitrate, potassium sorbate, vinegar are used for reduction of antimicrobial activity (Stanojevic et al., 2009). Vinegar is used as protection of fungal pathogens in indoor micro-organisms (Rogawansami et al., 2015). Sodium benzoate and acetic acid are the most advantageous preservatives used as safepesticides of fruit fungi (Nair, 2001). So, consider all of the above facts the present study dealt with the accurate identification based on morphological and molecular characterization, growth characteristics of the isolated fungus and the eco-friendly management practices.

\section{Materials and Methods}

Diseased samples were collected from trees located at Wildlife Rescue Centre (WRC) of Jahangirnagar University (JU), Bangladesh. Collected diseased fruits were separately packed in sterile polyethylene bags to avoid secondary infection. These samples then kept in the Laboratory of Mycology and Plant Pathology, Department of Botany, JU for further investigations. The method involved in studying the symptoms of amla fruit spot was conducted during the months of November 2016 to December 2017. Tissue planting methodwas used to isolate fungal pathogens; subculture was maintained on PDA medium; the pure culture was stored in refrigerator at $-4^{\circ} \mathrm{C}$. Isolated fungus from the infected tissues of amla fruit samples was identifiedbased on colony morphology, morphological characteristic of conidia. For molecular characterization, fungal genomic DNA samples were extracted using DNA extraction Kit (Promega, Madison, USA). DNA concentrations were measured using Nano Drop Spectrophotometer (ND200o, Thermo Scientific, USA).
The primer ITS4 (5-TCCTCCGCTTATTGATATG C-3) and ITS5 (5-GGAAGTAAAAGTCGTAACAA GG-3) were used for the PCR reaction (Sikder et al., 2019). PCR was performed using a thermal cycler (Veriti thermal cycler, Applied Biosystems, USA) with an initial denaturation stage of $5 \mathrm{~min}$ at $95^{\circ} \mathrm{C}$, followed by 35 cycles of denaturation for 30 sec at $94^{\circ} \mathrm{C}$, annealing for $30 \mathrm{sec}$ at $52^{\circ} \mathrm{C}$, extension for $1 \mathrm{~min}$ at $72^{\circ} \mathrm{C}$ and a final $10 \mathrm{~min}$ extension at $72^{\circ} \mathrm{C}$. Amplification products were analyzed by gel electrophoreses on a 1.5\% agarose gel with a $1 \mathrm{~kb}$ DNA ladder as a marker. The purified PCR products of approximately $650 \mathrm{bp}$ were sequenced by using 2 primers in First BASE Laboratories SdnBhd (Malaysia). Sequencing data were BLASTn searched on NCBI Genebank database. The phylogenetic analysis was conducted using MEGA 6 software.

Six different fungal culture media i.e. PDA, CA, PSA, RA, HPA, HA was used to assay the mycelial growth of the pathogen. The effects of temperature on the mycelial growth of Thielaviopsis paradoxa, experiment was conducted according to Alam et al. (2010). Different temperatures $\left(15,20,25,30\right.$ and $\left.35^{\circ} \mathrm{C}\right)$ was maintained for the mycelial growth of the pathogen on PDA in an incubator. The mycelial growth was recorded at 7 days post inoculation (dpi). The effect of light on the mycelial growth of the pathogen was done by exposing the inoculated culture to three different light regimes i.e. $24 \mathrm{~h}$ light, $24 \mathrm{~h}$ dark and $12 \mathrm{~h}$ light and $12 \mathrm{~h}$ dark in an growth chamber at room temperature $\left(25 \pm 2^{\circ} \mathrm{C}\right)$ was maintained (Singha et al., 2013). The effect of $\mathrm{pH}$ on the growth of the pathogen was assayed on PDA medium. Different pH levels viz., 5.0, 6.0, 7.0, 8.0 and 9.0 were used (Alam and Rahman, 2020).

A total of three extracts of plant parts namely, rhizome of turmeric- Curcuma longa L., seeds of black cumin- Nigella sativa L. and bulb of garlicAllium sativum L. were selected for the evaluation of the efficacy of aqueous plant extract against Thielaviopsis paradoxa. The desired part of each plant was thoroughly washed in tap water, air dried and then used for fresh extract preparation. Rhizome, seeds and bulb of that plant parts were prepared by crushing known weight of fresh materials with distilled water ratio of $1: 1(\mathrm{w} / \mathrm{v})$. The pulverized mass of a plant part was squeezed through fine cloth to remove particulate matter. The supernatants were filtered through filter paper. Finally, the requisite amount of the filtrate of each plant extract was mixed with PDA medium to get 10,20 and $30 \%$ concentrations. Medium was prepared with plant extract and poured into sterilized Petri plates and allowed to solidify. Then, test fungus was inoculated into Petri plates. Inoculated Petri plates were incubated at $25 \pm 2^{\circ} \mathrm{C}$ and measured the radial growth after 7 days of inoculation. 
A total of two preservative chemicals namelysodium benzoate and acetic acid (vinegar) were selected for evaluating their effects on the growth of test pathogens associated with amla fruits. Three different doses of these chemicals $(50,75$, $100 \mathrm{mM}$ ) were mixed with PDA, poured into sterilized Petri plates, and allowed to solidify. Inoculation, incubation, data were taken as similar to plant extracts. Inhibition percent was calculated by the following formulae-

$$
I=\frac{\mathrm{C}-T}{\mathrm{C}} x 100
$$

in which $I=$ percentage of mycelium growth inhibition; $C=$ growth of mycelium in control; and $T=$ growth of mycelium in treatments.

Data generated during the experiment were checked for normality and homogeneity of variance. Data on effects of culture media, light, temperature, $\mathrm{pH}$, hydrophilic plant extract, chemical preservatives on mycelial growth and inhibition of the mycelial growth of isolated pathogens were found to be normal and were analyzed using statistical package R.

\section{Results and Discussion}

Black colored spots with black margin appeared in the diseased amla with slightly sunken. Slow growing vegetative growth was found on PDA medium (Fig. 1). Mycelium is greyish in color on PDA. Conidiophores are straight, hyaline to light brown in color. Conidia are cylindrical-oval to ellipsoidal, light brown in color and in chain forms or scattered (Fig. 1). Once isolated, the fungus was identified as genus- Thielaviopsis, based on its morphological characteristics. The teleomorph of genus- Thielaviopsisis known as genus- Ceratocystis.
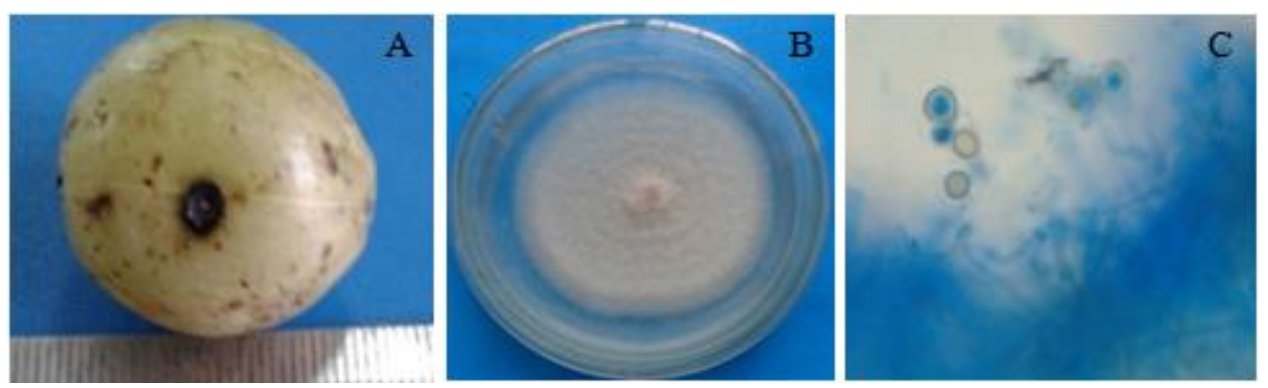

Fig. 1. Symptoms and morphological characteristics of black spot disease of amla fruits caused by Thielaviopsis paradoxa. A: Symptoms of black spot disease of amla fruits collected from trees; B: Vegetative growth of T. paradoxa on PDA medium, and C: Microscopic view of conidia and mycelium.

We received NCBI accession of the studied fungus- MH368110 Thielaviopsis paradoxa which showed $99 \%$ sequence similarity with KC415073.1 Ceratocystis paradoxa, KR183792.1 Thielaviopsis paradoxa and GU567771.1 Ceratocystis paradoxa. Once phylogenetic trees were generated after retrieving sequence data from NCBI, we further confirmed the homology with previously identified fungus (Fig. 2). In maximum parsimony tree, there was four different clades found in which our organism formed cluster with $T$. paradoxa (telomorph: $C$. paradoxa) group with bootstrap value of 94 . Second clades consist of $T$. thielavioides group; third group having T. resinifera group and forth groups with $T$. basicola group. ITS sequences are genetically constant or show little variation within species, but vary between species in a genus (Alam et al., 2009).Genetic diversity within a group is probably due to an efficient gene flow and to a high genetic compatibility within the strains tested.

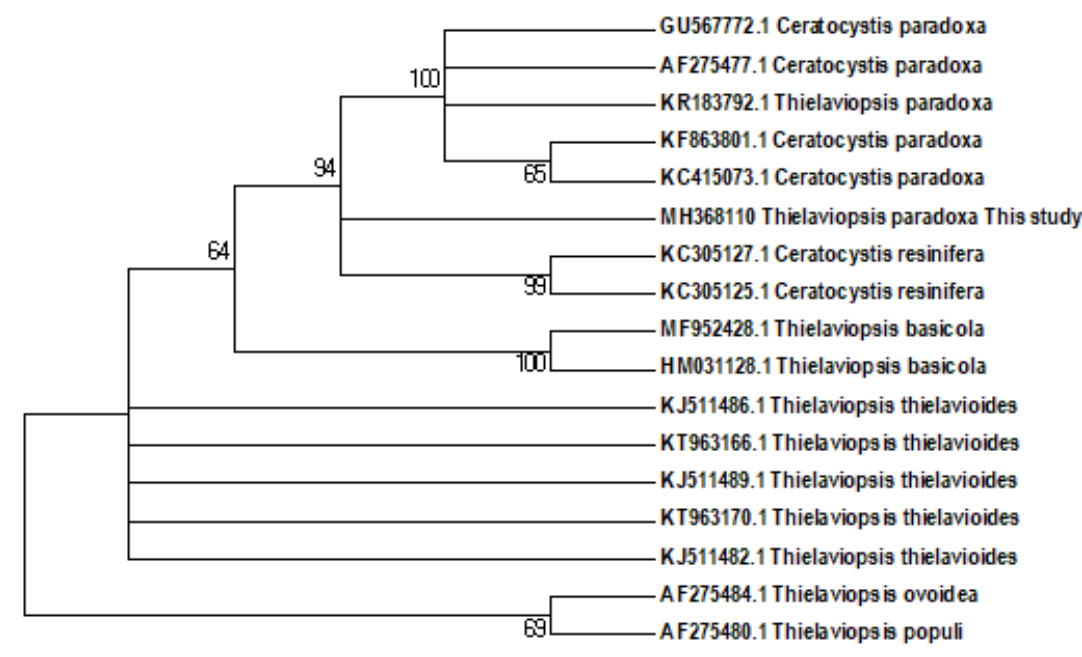

Fig. 2. Maximum parsimony tree of the $18 \mathrm{~S}$ rDNA sequence of the studied organism with bootstrap value. Our organism $\left(\mathrm{MH}_{3} 68110\right)$ market with this study. 
The association of Thielaviopsis paradoxa was confirmed by pathogenicity test through Koch Postulates.In our experiment, detached fruit inoculation technique was used. The inoculated fruits were kept in laboratory conditions $\left(25 \pm 2^{\circ} \mathrm{C}\right)$ for seven days and pathogens were reisolated. Earlier workers had described similar technique. The pathogenicity of the isolated fungus was tested following modified "detached leaf technique" and inoculated fungal block as described by Aktar and Shamsi (2014) in their experiment.

The effect of six different culture media viz., PSA, RA, CA, PDA, HPA and HA on mycelial growth of Thielaviopsis paradoxa was evaluated and the statistical differences among the culture media was found at 7 days post incubation (dpi) (Fig. 3). The greatest mean vegetative growth $(79.83 \mathrm{~mm})$ of the tested fungus was found on RA medium which is statistical significance compared to others media evaluated at $7 \mathrm{dpi}$. The second mycelial growth of the fungus was obtained on CA media. Most extensively used media-PDA did not supported profuse mycelial growth and the lowest mycelial growth $(50.67 \mathrm{~mm})$ was found on
HPA medium at 7 dpi. There was difference among six different culture media based on the color and pattern on mycelial growth. The color of the studied fungus was greyish on PSA, RA, CA and PDA; on the other hand, it was whitish in color on both HPA and HA media. The fluffy pattern of the mycelial growth was observed in case of HPA and HA media (Fig. 4). Present results in partially agreement with the findings of Javaid and Rauf (2015), which tested six different media (solid and broth) in which malt extract agar media supported the best growth of Ceratocystis manginecans, followed by carrot juice agar. In another study, potato dextrose agar amended with streptomycin (SPDA) media and carrot discs technique were used for isolation of Ceratocystis fimbriata during their research work (Masood et al., 2010) in which carrot provided the significantly higher frequency of $C$. fimbriata growth. Our results are contradictory with the findings of Bijaya (2005) who tested ten different fungal culture media in which PDA was found as best media for the growth and sporulation of T. paradoxa.

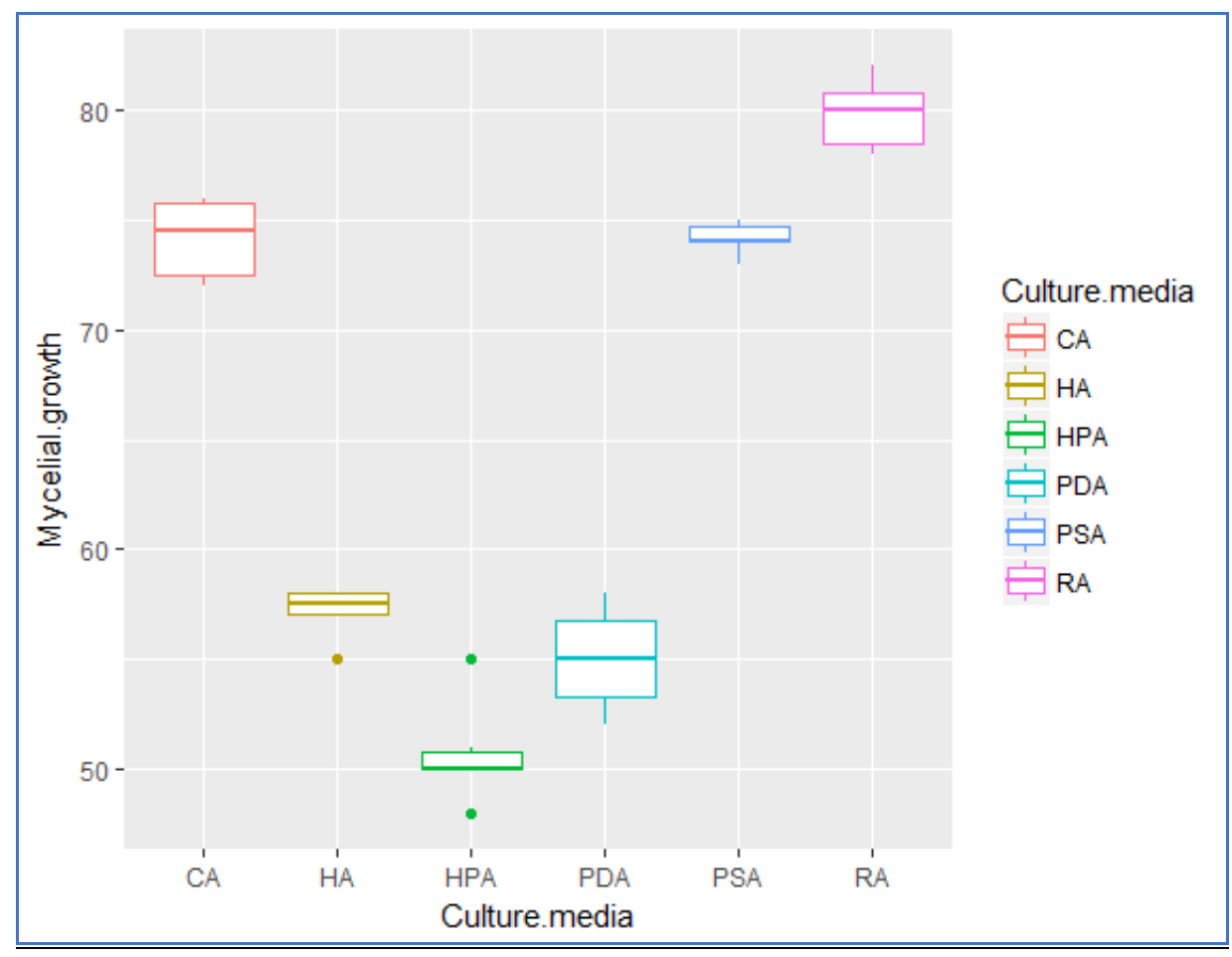

Fig. 3. Effect of culture media on mycelial growth (mm) of Thielaviopsis paradoxa. Value represents in box-plot as mean, $1^{\text {st }}$ quartile and $3^{\text {rd }}$ quartile of six replications. CA, Carrot agar; HA, Hansen's agar; HPA, Honey peptone agar; PSA, Potato sucrose agar; RA, Richard agar. 

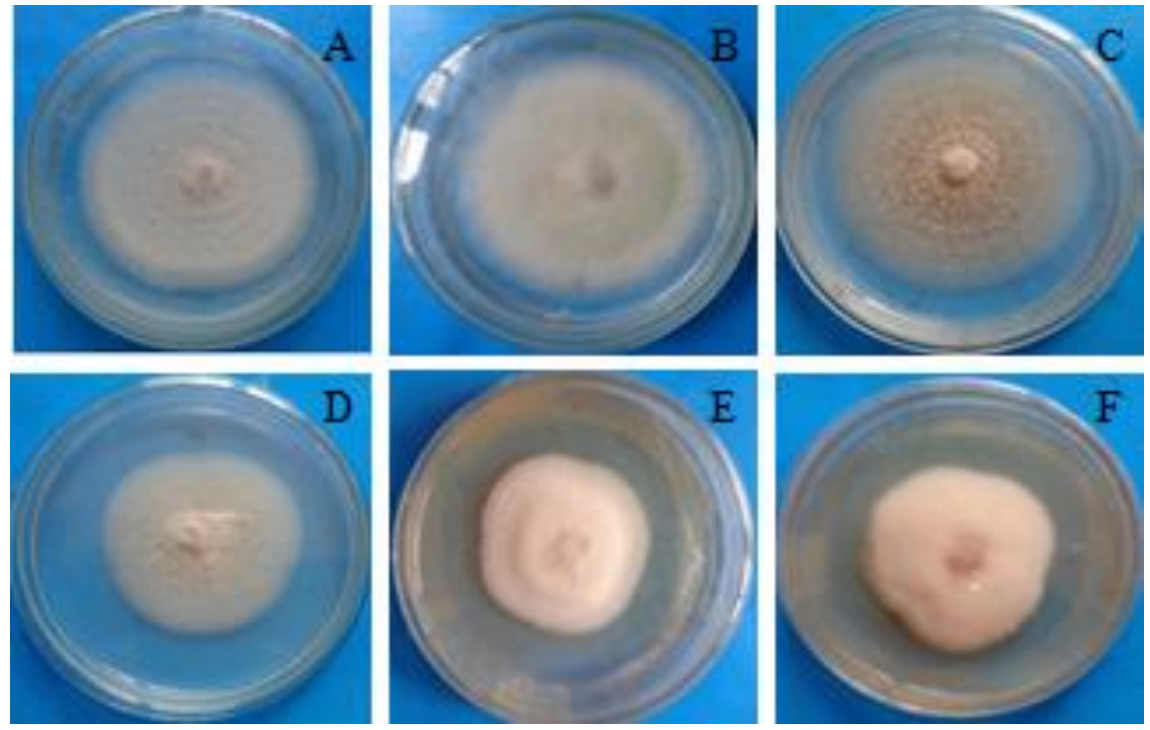

Fig. 4. Effect of culture media on mycelial growth of Thielaviopsis paradoxa at 7 dpi. A, Potato sucrose agar; B, Richard agar; C, Carrot agar; D, Potato dextrose agar; E, Honey peptone agar; and F, Hansen's agar.

In current study, the optimum temperature for vegetative growth of the studied fungus was obtained in the range of 15 to $35^{\circ} \mathrm{C}$, which was significantly differ from 15 and $20^{\circ} \mathrm{C}$ at $7 \mathrm{dpi}$ (Fig. 5). At $15^{\circ} \mathrm{C}$ temperature, the mycelial growth was inhibited extremely, maximum mycelia growth was recorded at $35^{\circ} \mathrm{C}$. Present results are in conformity with the findings of Tzeng and Sun (2010), which cited that the optimum temperature for hyphal growth of Thielaviopsis paradoxa was found at 25 to $30^{\circ} \mathrm{C}$.This fungus

higher than $35^{\circ} \mathrm{C}$. Yadahalli et al. (2007) reported the maximum vegetative growth of Thielaviopsis paradoxa, causing sett rot of sugarcane, at temperature of $25-30^{\circ} \mathrm{C}$. The optimum temperatures are important criteria for understanding the ecology of spoilage fungi, especially mycotoxigenic species as mentioned by Ahmed and Naresh (2009). There is always an optimum temperature for the best growth of any fungus as temperature has a regulatory effect on fungal growth and development. did not grow at temperatures lower than $10^{\circ} \mathrm{C}$ or

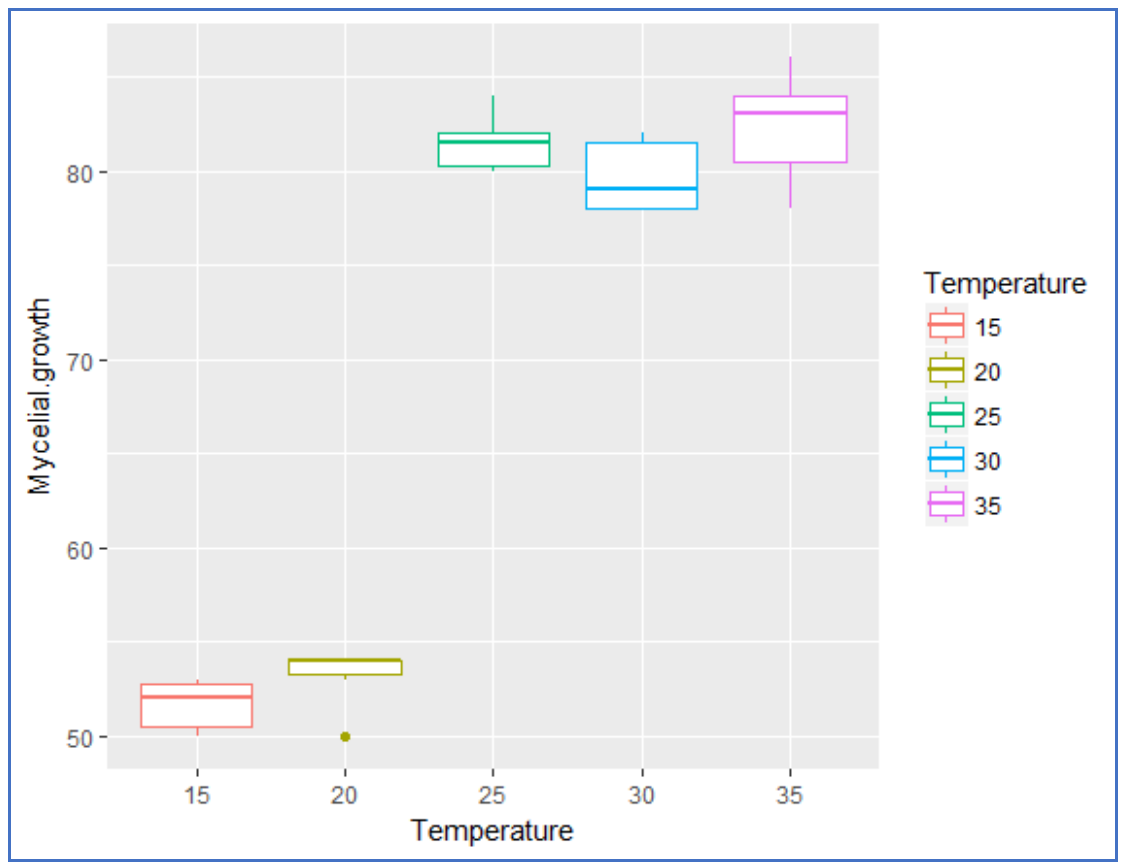

Fig. 5. Effect of temperature on mycelial growth $(\mathrm{mm})$ of Thielaviopsis paradoxa under five different temperature conditions at $7 \mathrm{dpi}$. Value represents in box-plot as mean, $1^{\text {st }}$ quartile and $3^{\text {rd }}$ quartile of six replications. 
Light is a very important signal for every living cell, and since optimal adaptation to both the beneficial and harmful effects of light significantly enhances fitness of an organism, it can be considered crucial for successful competition and survival in nature. The experimental plates were exposed and incubated under three different light conditions viz., 24 hours light (complete light), 24 hours dark (complete dark) and 12/12 hours alternate cycle of light and dark. Significance difference was observed among three different treatments (Fig. 6). Under $12 / 12$ hours light-dark condition, Thielaviopsis paradoxa showed the outmost mycelial growth $(90 \mathrm{~mm})$, followed by $76 \mathrm{~mm}$ under complete dark condition at 7 dpi. Interestingly, the mycelial growth was suppressed $(66.50 \mathrm{~mm})$ under complete light exposure condition at $7 \mathrm{dpi}$. Our results are partially supported by Bachiller (1998), who reported that continuous light as well as alternate light and darkness greatly boosted the vegetative growth and sporulation of $C$. paradoxa on PDA. Sporulation of this fungus was good at both continuous light and alternate cycles of light and darkness. Results revealed that T. paradoxa grew well and sporulated more in alternate light and dark for $12 \mathrm{~h}$, but fewer sporulations was observed in continuous light.

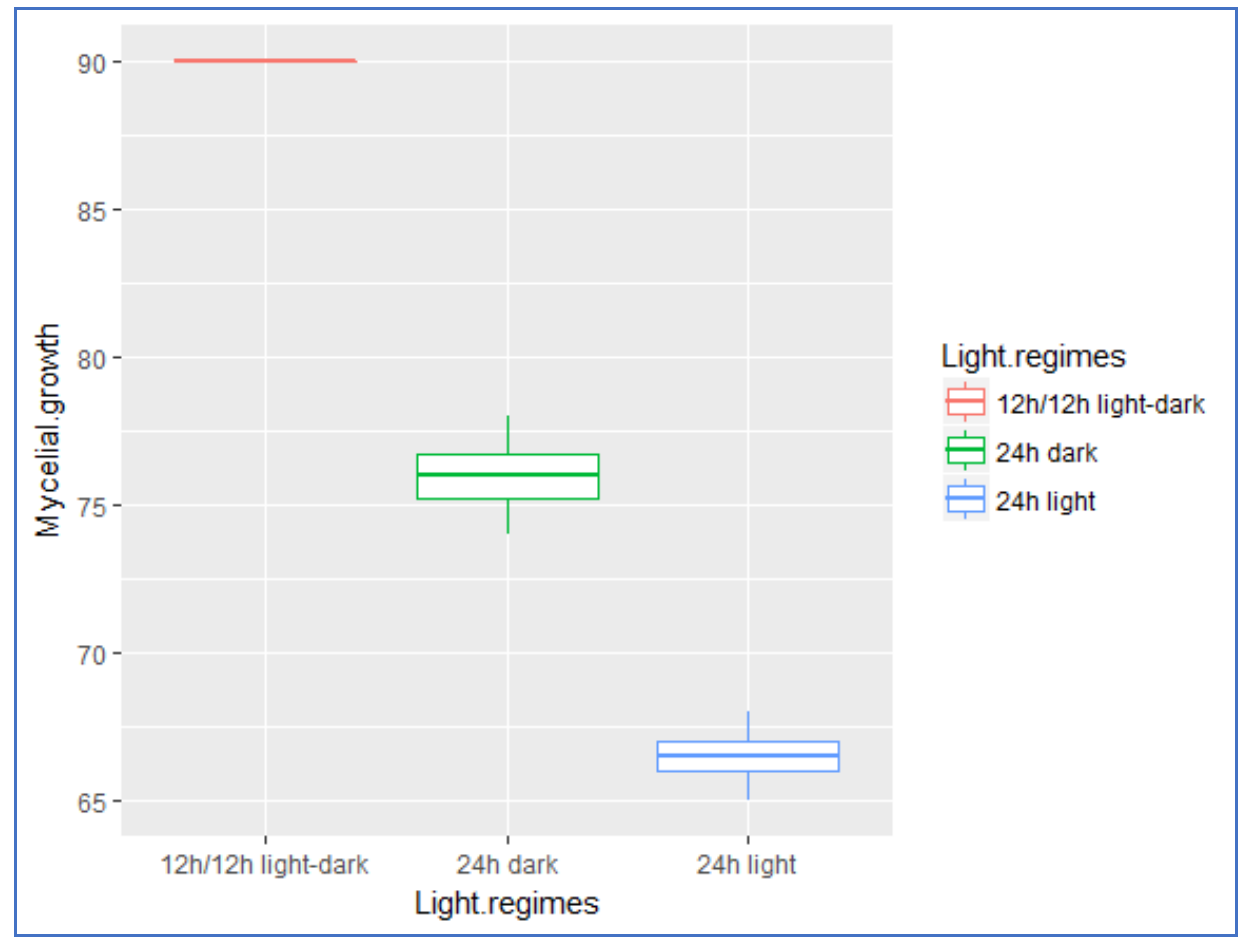

Fig. 6. Effect of light on mycelial growth $(\mathrm{mm})$ of Thielaviopsis paradoxa under different light regimes at $7 \mathrm{dpi}$. Value represents in box-plot as mean, $1^{\text {st }}$ quartile and $3^{\text {rd }}$ quartile of six replications.

$\mathrm{pH}$ is also one of key criteria for understanding the ecology of spoilage fungi, however, in present study, the experimental plates were incubated at five different $\mathrm{pH}$ level viz., 5, 6, 7, 8 and 9 . Growth of Thielaviopsis paradoxa was suppressed at $\mathrm{pH} 5$, intermediate growth pattern observed from $\mathrm{pH} 6$ to $\mathrm{pH} 8$, and the maximum mycelial growth was found at pH9 (Fig. 7). These results are in disagreement with the earlier reports of Sonyal et al. (2015) who obtained the maximum growth of Ceratocystis fimbriata at $\mathrm{pH} 7.5$, followed by $\mathrm{pH} 7.0$ and $\mathrm{pH}$ 8.0. The growth of the fungus was declined from $\mathrm{pH} 5.5$ to pH 2.0 and above pH 9.o. Yadahalli et al.(2007) noticed the maximum mycelial growth of Ceratocystis paradoxa when the $\mathrm{pH}$ of the media was between 6.0 and 7.5. Result indicated that this grew well at basic condition. 


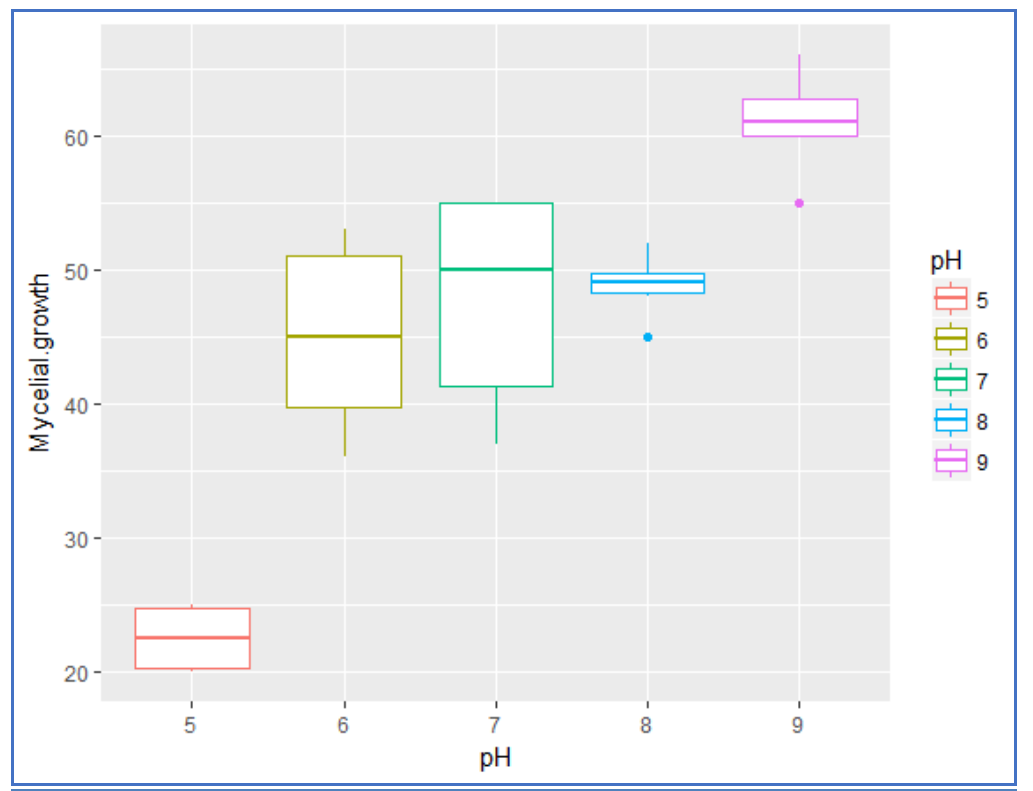

Fig. 7. Effect of $\mathrm{pH}$ on mycelial growth $(\mathrm{mm})$ of $P$. Thielaviopsis paradoxa under five different $\mathrm{pH}$ conditions at 7 dpi. Value represents in box-plot as mean, $1^{\text {st }}$ quartile and $3^{\text {rd }}$ quartile of six replications.

Three different concentrations (10\%, 20\% and $30 \%$ ) of the selected plant parts namely, rhizome of turmeric- Curcuma longa L., seeds of black cumin- Nigella sativa L. and bulb of garlicAllium sativum L. were used for evaluation of efficacy on the mycelial inhibition of Thielaviopsis paradoxa. There were positive trends of mycelial growth inhibition were noticed with increasing doses of plant extract. Both turmeric and black cumin did not able to inhibit mycelial growth at $10 \%$ and $20 \%$ crude extracts concentration (Fig. 8). However, only higher concentration (30\%) provided a certain level of mycelial inhibition of tested fungus. Interestingly, there was increasing trends of mycelial growth inhibition of tested fungi with increasing concentration of garlic. Garlic extract provided positive results in respect of vegetative growth inhibition of $T$. paradoxa in which around $80 \%$ mycelial growth restriction was recorded due to higher dose of garlic, followed by
$78 \%$ and $65 \%$ for $20 \%$ and $10 \%$ garlic crude extract, respectively (Fig. 8). In our study, there were no striking outcomes of the efficacy of black cumin and turmeric crude extracts. However, earlier workers had been reported the positive impact of those plant extract. Shokri et al. (2012) reported that the major components of the essential oil obtained from black cumin seeds are thymoquinone, $\mathrm{p}$-cymene, trans-anethole and $\mathrm{\gamma}$ terpinene. These components possessed moderate in vitro and in vivo inhibitory activity against pathogenic yeasts, dermatophytes, nondermatophytic filamentous fungi and aflatoxinproducing fungi. Present studies regarding the significant impact of garlic on the tested fungus are in conformity with earlier reports. It has been reported that garlic contains of more than 200 compounds, some of which are volatile substances such as allicin, ajoene and alliin, which is considered to be the main active ingredient in garlic (Goncagul and Ayaz, 2010).

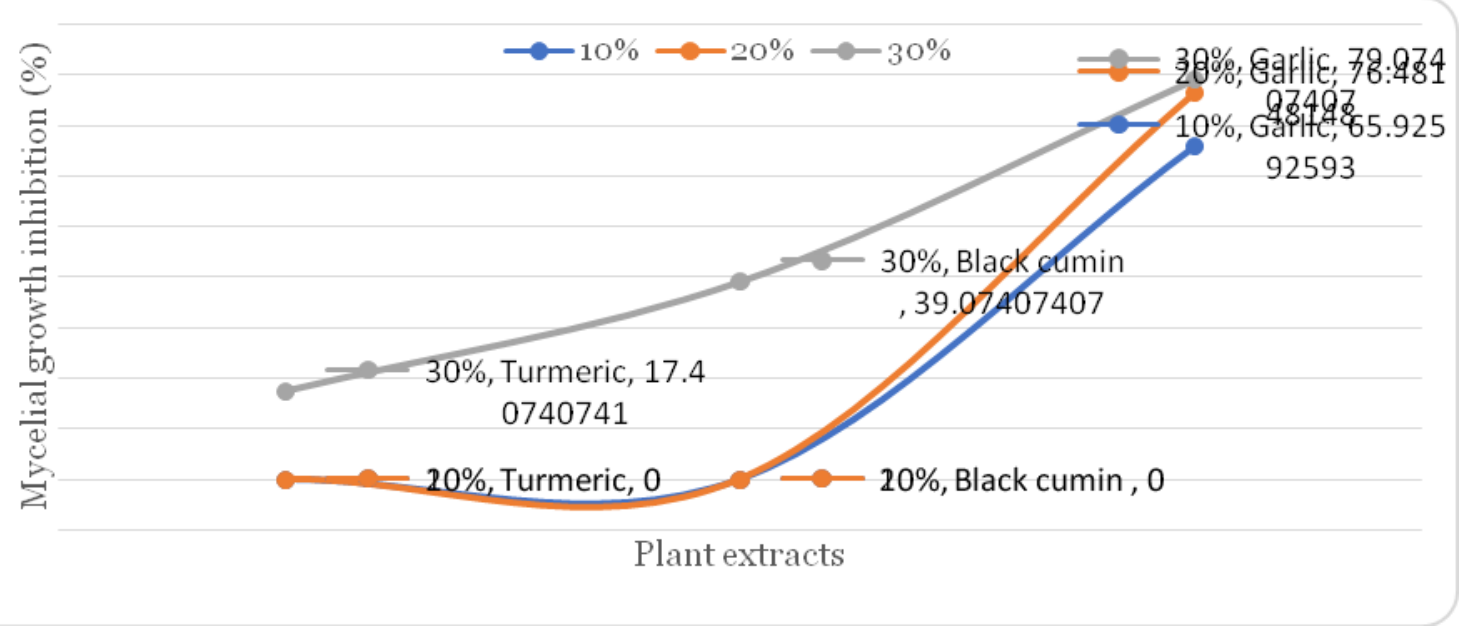

Fig. 8. Effect of selected plant parts extracts on mycelial growth of Thielaviopsis paradoxa at 7 dpi. 
Preservative agents commonly used include weak organic acids such as acetic, lactic, benzoic and citric acids, which inhibit the microbial growth in various foods. In the present study, there was an increasing trends of mycelial growth inhibition observed with increasing doses of food preservatives (Fig. 9). Lower doses (50 and 75 $\mathrm{mM}$ ) of vinegar (acetic acid) did not show promising inhibition of the tested fungus. However, fifty percent mycelial inhibition of Thielaviopsis paradoxa was recorded by higher dose (100 mM concentration) of vinegar. On the other hand, sodium benzoate showed very striking results. Lower dose $(50 \mathrm{mM})$ of sodium benzoate was able to restrict $80 \%$ mycelial growth of the studied fungus and the higher dose (100 $\mathrm{mM}$ ) was completely inhibited the vegetative growth of it (Fig. 9). The effect of organic acids on the fungal growth, which contaminate food and feed, have been investigated by several authors (Gupta et al., 2012; Khosravi et al., 2013). Organic acids, which used in food preservation is considered; simple, fast, acid, cheap and efficient. Moreover, most of them are not limited in the acceptable daily intake for humans. These characteristics favour their use in food preservation.

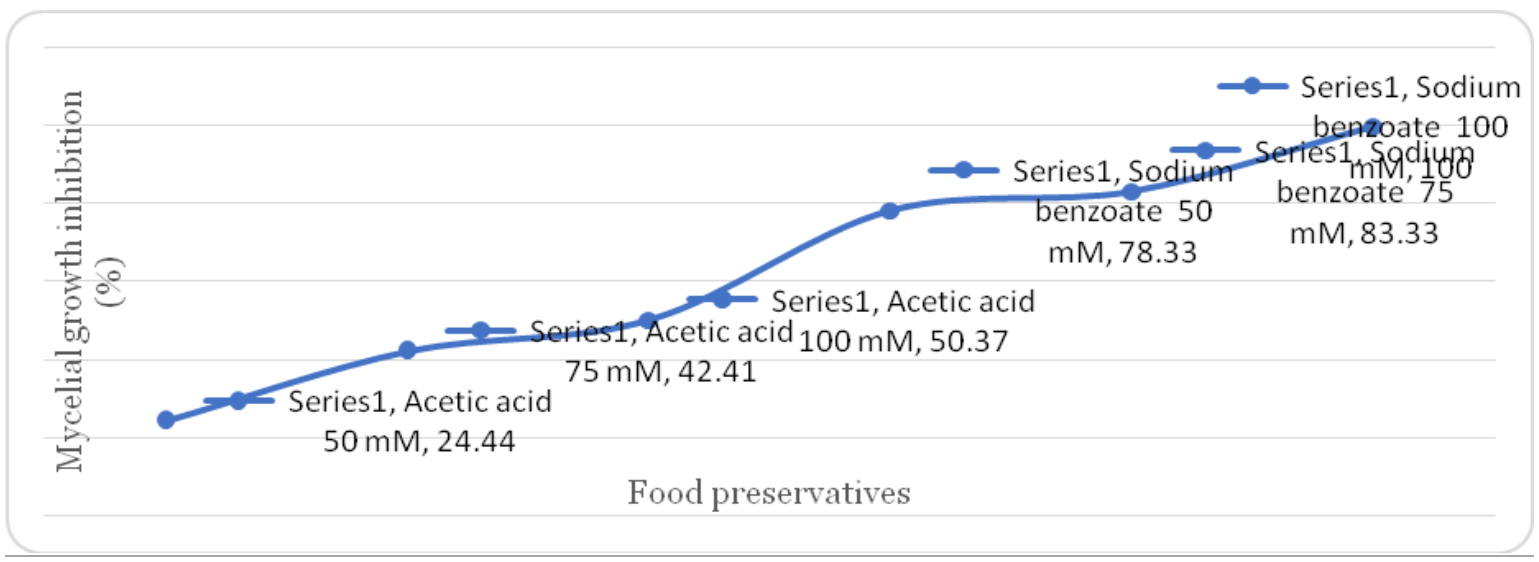

Fig. 9.Effect of acetic acid and sodium benzoate on mycelial growth of Thielaviopsis paradoxa at $7 \mathrm{dpi}$.

Based on molecular identification, our isolated fungus was identified as Thielaviopsis paradoxa. To our knowledge, this is the first report of Thielaviopsis paradoxa (telemorph: $C$. paradoxa) causing black spot disease on amla fruits in Bangladesh.

\section{References}

Ahmed, A. and Naresh, M. 2009. Influence of physiological factors on growth, sporulation and ochratoxin A/B production of new Aspergillus ochraceus grouping. World Mycotoxin J. 2(4): 429-434. https://doi.org/ 10.3920/WMJ2009.1156

Aktar, M. and Shamsi, S. 2014. Report on alternaria blight of $T$. erecta and T. patula caused by Alternaria alternata (Fr.) Keissier. J. Asiat. Soc. Bangladesh Sci. 40(1): 133-140.

https://doi.org/10.3329/jasbs.v40i1.31740

Alam, N. and Rahman, F. 2020. Optimum vegetative growth conditions and genetic diversity in different strains of Pleurotus salmoneastramineus L.J.N. Vassilzeva. Bangladesh J. Bot. 49(1): 125-134. https://doi.org/10.3329/bjb.v49i1.49119

Alam, N., Cha, Y.J., Shim, M.J., Lee, T.S. and Lee, U.Y. 2010. Cultural conditions for mycelial growth and molecular phylogenetic relationship in different wild strains of Schizophyllum commune. Mycobiol. 38(1): 17-25.

https://doi.org/ 10.4489/ MY CO.2010.38.1.017

Alam, N., Shim, M.J., Lee, M.W., Shin, P.G., Yoo, Y.B. and Lee, T.S. 2009. Phylogenetic relationship in different commercial strains of Pleurotus nebrodensis based on ITS sequence and RAPD. Mycobiol. 37(3): 183188.

https://doi.org/10.4489/MYCO.2009. 37.3.183

Bachiller, N.C.S.J. 1998. Effect of environmental factors on the growth and sporulation of Thielaviopsis paradoxa (de Seynes) Von Hohnel in culture. Philipp. J. Crop Sci. 23: 43.

Bijaya, H.K. 2005. Studies on sett rot of sugarcane and its management with special reference to Acetobacter diazotrophicus Gillis and de Ley. MS Thesis, Department of Plant Pathology, College of Agriculture, Dharwad University of Agricultural Science, Dharwad-580005. p. 95.

Daniel, C.K., Leenox, C.L. and Vries, F.A. 2015. In vitro effects of garlic extracts on pathogenic fungi Botrytis cinerea, Penicillium expansum and Neofabraea alba. South Afr. J. Sci. 111(7-8): 1-8.

Dasaroju, S. and Gottumukkala, K.M. 2014. Current trends in the research of Emblica officinalis (Amla): A Pharmacological Perspective. Int. J. Pharm. Sci. Rev. Res. 24(2): 150-159.

Engelbrecht, C.J.B., Harrington, T.C., Alfenas, A.C. and Suarez, C. 2007. Genetic variation in populations of the cacao wilt pathogen, Ceratocystis cacaofunesta. Plant Pathol. 56(6): 923-933. https://doi.org/10.1111/j.1365-3059.2007.01735.x

Goncagul, G. and Ayaz, E. 2010. Antimicrobial effect of garlic (Allium sativum) and traditional medicine. J. Anim. Vet. Adv. 9: 14. https://doi.org/10.3923/javaa.2010.1.4 
Gupta, S., Satishkumar, M.N., Duraiswamy, B., Das, S. and Chhajed, M. 2012.Potential herbs and its phytoconstituents against fungal infection: A systematic review. World J. Pharm. Res. 1: 1-20.

Javaid, A. and Iqbal, D. 2014. Management of collar rot of bell pepper (Capsicum annuum L.) by extracts and dry biomass of Coronopus didymus shoot. Biol. Agric. Hortic. 30(3): 164-172. https://doi.org/10.1080/01448765.2014.886528

Javaid, A. and Rauf, S. 2015. Management of basal rot disease of onion with dry leaf biomass of Chenopodium album as soil amendment. Int. J. Agric. Biol. 12(5): 22-27.

Khosravi, A.R., Shokri, H., Farahnejat, Z., Chalangari, R. and Katalin, M. 2013. Antimycotic efficacy of Iranian medicinal plants towards dermatophytes obtained from patients with dermatophytosis. Chinese J. Nat. Medicine. 11: 43-48.

https://doi.org/ 10.1016/S1875-5364(13)60006-0

Krishnaveni, M. and Mirunalini, S. 2012. Chemopreventive efficacy of Phyllanthus emblica L. (amla) fruit extraction 7, 12dimethylbenz (a) anthracene induced oral carcinogenesis- A dose-response study. Environ. Toxicol. Pharmacol. 34(3): 801-10. https://doi.org/10.1016/j.etap.2012.09.006

Masood, A., Saeed, S., Iqbal, N., Malik, M.T. and Kazmi, M.R. 2010 Methodology for the evaluation of symptoms severity of mango sudden death syndrome in Pakistan. Pak. J. Bot. 42(2): 1289-1299.

Moghadamtousi, S.Z., Kabir, H.A., Hassandarvesh, P., Hassan, T., Abu-bokkor, S. and Zandi, K. 2014. A review on antibacterial, antiviral and antifungal activity of Curcumin. Hindwai Publication Corporation. BioMed. Res. Int. Article ID 186864: 1-12. https://doi.org/10.1155/2014/ 186864

Nair, P.B. 2001. Final report on the safety assessment of benzyl alcohol, benzoic acid, sodium benzoate. Int. J. Toxicol. 20(3): 2350. https://doi.org/10.1080/10915810152630729

Oliveira, L.S.S., Harrington, T.C., Ferreira, M.A., Freitas, A.C. and Alfenas, A.C. 2018. Populations of Ceratocystis fimbriata on Colocasia esculenta and other hosts in the Mata Atlântica region in Brazil. Plant Pathol. 67(1): 97-106. https://doi.org/10.1111/ ppa.12706

Paulin-Mahady, A.E., Harrington, T.C. and McNew, D. 2002. Phylogenetic and taxonomic evaluation of Chalara, Chalaropsis, and Thielaviopsis anamorphs associated with Ceratocystis. Mycologia. 94(1): 62-72.

https://doi.org/10.1080/15572536. 2003.11833249

Piveta, G., Ferreira, M.A., Muniz, M.F.B., Valdetaro, D., Valdebenito-Sanhuera, R., Harrington, T.C. and Alfenas, A.C. 2016. Ceratocystis fimbriata on kiwi fruit (Actinidia spp.) in Brazil. New Zeal. J. Crop Hort. Sci. 44(1):1-12.

https://doi.org/10.1080/01140671.2016.1143020
Rogawansami, S., Gaskin, S., Taylor, M. and Pisaniello, D. 2015. An evaluation of antifungal agents for the treatment of fungal contamination in indoor air environments. Int. J. Environ. Res. Public Health. 12(6): 6319-6332.

https:// doi.org/ 10.3390/ ijerph 120606319 Shokri, H., Sharifzadeh, A. and Tamai, A.I. 2012. Anti-Candida zeylanoides activity of some Iranian plants used in traditional medicine.J. Mycol. Méd. 22(3): 211-216. https://doi.org/10.1016/j.mycmed.2012.04.006

Sikder, M.M., Mallik, M.R.I. and Alam, N. 2019. Identification and in vitro growth characteristics of entomopathogenic fungusAschersonia sp. in Bangladesh. Adv. Zool. Bot. 7(1): 11-18.

https://doi.org/10.13189/azb.2019.070102

Singh, D. and Sharma, R.R. 2007. Postharvest diseases of fruit and vegetables and their management. In: Prasad, D. (Ed.), sustainable pest management. Daya Publishing House, New Delhi, India. p. 105.

Singha, S.M., Alam, N., Sarker, N.C. and Shaheen, M. 2013. Influence physicchemical conditions culture medium on in vitro mycelial growth in different strains of Volvariella volvaceae. Bangladesh J. Mush. 7(2): 59-66.

Sonyal, S., Pappachan, A., Palanna, K.B., Mahesha, Manjunath, H.S., Hurakadli, S. and Giri, M.S. 2015. Survival ability of Ceratocystis fimbriata causing pomegranate wilt in different temperature and hydrogen ion concentration (pH). Int. J. Pure Appl. Biosci. 3(4): 49-53.

Stanojevic, D., Comic, L., Stefanovic, O. and Solujic-Sukdolak, S.I. 2009. Antimicrobial effects of sodium benzoate, sodium nitrite and potassium sorbate and their synergistic action in vitro. Bulg. J. Agric. Sci. 15: 307311.

Tzeng, S.J. and Sun, E.J. 2010.First report of fruit basal rot by Ceratocystis paradoxa on coconut in Taiwan. Plant Dis. 94(4): 487. https://doi.org/10.1094/PDIS-94-4-0487C

Verma, P. and Verma, B.K. 2015.A new preharvest fruit rot of Aonla (Emblica officinalis) caused by Pestalotiopsis versicolor from central India. World $J$. Pharma. Res. 4(10): 2461-2465.

Wyk, V.M., Al-Adawi, A.O., Khan, I.A., Deadman, M.L., Al-Jahwari, A.A., Ploetz, R., Wingfield, B.D., Al-Subhi, A.M. and Wingfield, M.J. 2007. Ceratocystis manginecans sp. Nov., causal agent of a destructive mango wilts disease in Oman and Pakistan. Fungal Divers. 27: 213-230.

Yadahalli, K.B., Adiver, S.S. and Kulkarni, S. 2007. Effect of $\mathrm{pH}$, temperature and relative humidity on growth and development of Ceratocystis paradoxa - a causal organism of pineapple disease of sugarcane. Karnataka J. Agric. Sci. 20(1): 159-161. 